\title{
As Escritas Coreana e Japonesa: Dois Caminhos Tradutórios
}

\author{
Yun Jung Im
}

Resumo: Por muito tempo, os coreanos e os japoneses tiveram a escrita chinesa como a única forma de documentação, instrução, educação, enfim, da cultura letrada. Visto de outro ângulo, os coreanos e os japoneses, falantes de duas línguas ural-altaicas, eram obrigados a escreverem em outra língua, da família sino-tibetana. É desse descompasso que ambos acabarão por desenvolver as suas próprias escritas tendo como ponto de partida a chinesa, processo no qual são revelados modos diferentes de lidar com essa diferença, dando, inclusive, margem a ricos ensaios em estudos culturais.

Palavras-chave: Alfabeto coreano, silabário japonês, ideograma chinês, tradução.

\section{INTRODUÇÃO}

Parto da premissa de que a abordagem da tradução pode ser tão ampla quanto o alcance da imaginação. Assim, proponho considerar as escritas coreana e japonesa como duas formas distintas de tradução tendo como a escrita-fonte a chinesa, uma vez que as duas revelam dois caminhos distintos de trazer a escrita chinesa para sua realidade.

Algumas das características da escrita chinesa já são amplamente conhecidas: que é formada por ideo-gramas, picto-gramas e combinação entre eles (embora em muitos casos tanto os ideogramas quanto os pictogramas possam ser usados basicamento pelo seu valor sonoro); que, por não se tratar de uma representação do som, não há uma tabela de correspondência fonética, exigindo que o leitor conheça a leitura exata dos ideogramas um a um; que é tonal, possuindo 4 tons distintivos. 
Por muito tempo, tanto os coreanos quanto os japoneses tiveram essa escrita "importada" como a única forma de documentação, instrução, educação, enfim, da cultura letrada, e é de se esperar que tenha sido exclusividade da classe nobre masculina. Visto de outro ângulo, os coreanos e os japoneses, falantes de duas línguas ural-altaicas, eram obrigados a escrever em outra língua, da família sinotibetana. É desse descompasso que ambos acabarão por desenvolver as suas próprias escritas tendo como ponto de partida a chinesa, processo no qual são revelados modos diferentes de lidar com essa diferença, dando, inclusive, margem a ricos ensaios em estudos culturais.

\section{A(S) ESCRITA(S) JAPONESA(S)}

Figura 1: Hiragana




Figura 2: Katana

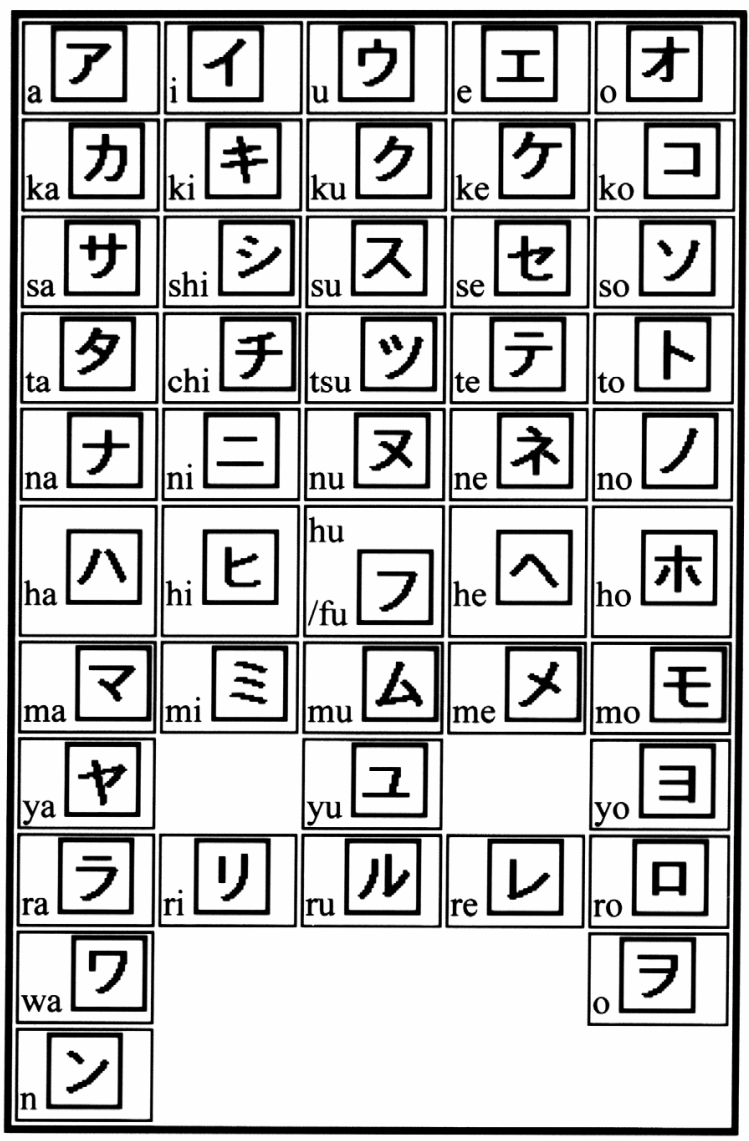

No Japão, os silabários kana - o hiragana e o katakana - desenvolveram-se na era Heian (794-1192) em dois veios bem distintos. O silabário hiragana surgiu entre as mulheres da corte proibidas de estudarem a escrita chinesa, e sabe-se que são estilizações simplificadas de alguns ideogramas chineses, selecionados pela semelhança sonora com a sílaba em questão. Assim, a sílaba la (ra), ら, seria um derivado de 良, que se lê liáng em chinês, e a sílaba ya, や, seria do ideograma 也, que se lê yě em chinês.

O katakana por sua vez desenvolveu-se entre os monges com o fim de facilitar a leitura dos sutras. Não cabe aqui um rastreamento histórico de cada 
silabário, mas o sistema que veio a se consolidar como a escrita japonesa é uma combinação dos silabários hiragana, katakana, além dos próprios ideogramas chineses. O silabário katakana é utilizado para grafar palavras de origem estrangeira. O hiragana, por sua vez, é usado principalmente para as desinências, partículas, sufixos, flexões, verbos de ligação, enfim, os elementos sintáticogramaticais, ficando os ideogramas chineses com o grosso dos elementos lexicais. Resumindo, os ideogramas chineses fazem parte orgânica do texto, desempenhando o papel de peças-chave, enquanto que o hiragana funciona como um "cimento" que dá liga a esses elementos lexicais. Seja com palavras grafadas em katakana (no caso de palavras estrangeiras), seja com os ideogramas chineses, o hiragana cumpre um papel eminentemente extra-lexical, salvo poucos casos de palavras nativas. É uma solução bastante fácil e lógica para uma língua aglutinante e rica em elementos extra-lexicais, quesito em que o chinês é extremamente econômico.

Figura 3: exemplo de um texto japonês

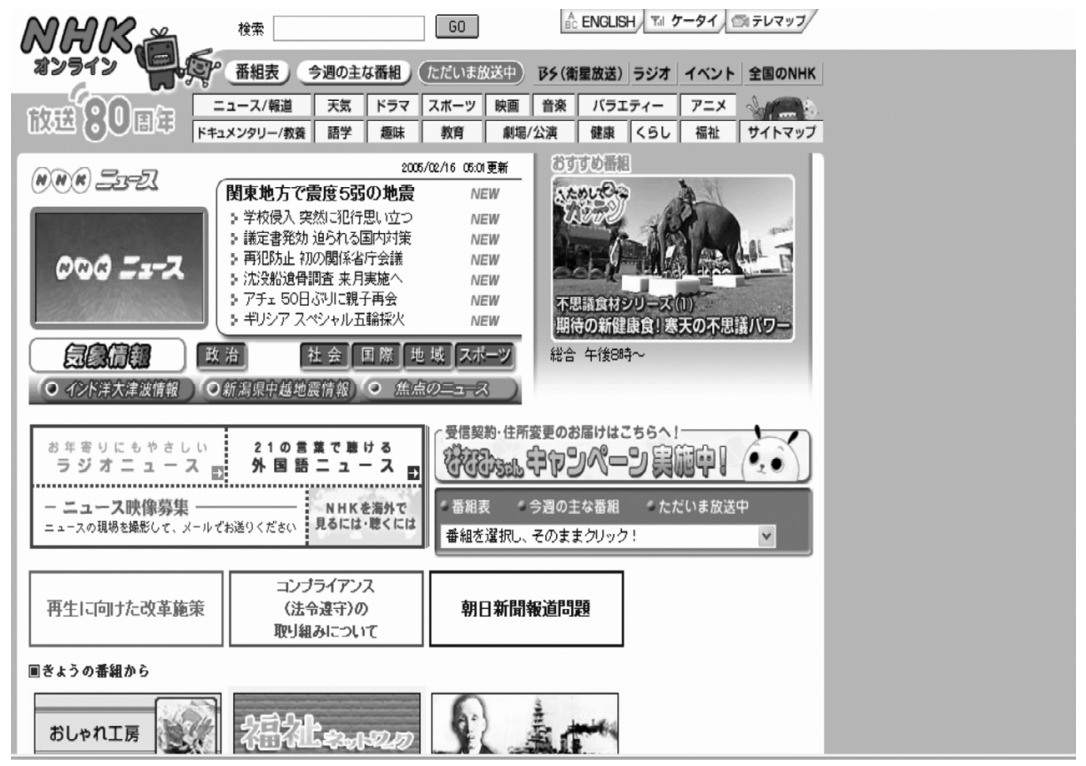




\section{Hangul, o alfabeto coreano}

\begin{tabular}{|c|c|c|c|c|c|c|c|c|c|c|c|}
\hline \multirow{2}{*}{\multicolumn{2}{|c|}{ Konson. }} & r & F & -1 & F & $\perp$ & II & $T$ & $\pi$ & - & 1 \\
\hline & & $\mathrm{a}$ & ya & $\breve{0}$ & yeo & 0 & yo & $u$ & yu & eu & $\mathrm{i}$ \\
\hline T & $g(k)$ & 가 & 갸 & 거 & 겨 & 고 & 교 & 구 & 규 & 그 & 기 \\
\hline $\mathbf{L}$ & $\mathrm{n}$ & 나 & 냐 & 녀 & 녀 & 노 & 뇨 & 누 & 뉴 & 느 & 니 \\
\hline$ᄃ$ & $\mathrm{~d}$ & 다 & 댜 & 더 & 뎌 & 도 & 乒 & 두 & 듀 & 드 & 다 \\
\hline 己 & $r(1)$ & 라 & 랴 & 러 & 려 & 로 & 료 & 루 & 류 & 르 & 리 \\
\hline 口 & $\mathrm{m}$ & 마 & 먀 & 머 & 며 & 모 & 묘 & 무 & 뮤 & 므 & 미 \\
\hline H & $b$ & 바 & 뱌 & 버 & 벼 & 보 & 뵤 & 부 & 开 & 브 & 비 \\
\hline 入 & $s$ & 사 & 샤 & 서 & 셔 & 소 & 企 & 車 & 슈 & 스 & 시 \\
\hline 0 & 劵 & 아 & 야 & 어 & 여 & 오 & 요 & 우 & 유 & 으 & 이 \\
\hline ス & $j$ & 자 & 쟈 & 저 & 져 & 조 & 歪 & 주 & 쥬 & 즈 & 지 \\
\hline ᄎ & $\mathrm{ch}$ & 차 & 챠 & 처 & 쳐 & 초 & 쵸 & 추 & 츄 & 츠 & 치 \\
\hline न & $\mathrm{k}$ & 카 & 캬 & 커 & 켜 & 고 & 쿄 & 쿠 & 큐 & 크 & 키 \\
\hline$E$ & $\mathrm{t}$ & 타 & EF & 터 & 텨 & 토 & 豆 & 투 & 튜 & EE & El \\
\hline$\overline{\mathbf{1}}$ & $\mathrm{p}$ & 파 & $\overline{1} f$ & 퍼 & 펴 & 포 & 吾 & 푸 & 퓨 & 프 & $\overline{2}]$ \\
\hline$\div$ & $\mathrm{h}$ & 하 & 햐 & 허 & 혀 & 호 & $\overline{\overline{8}}$ & 후 & 휴 & $\overline{\bar{D}}$ & 히 \\
\hline
\end{tabular}

Figura 4: Hangul

O hangul é provavalmente o único sistema de escrita deliberadamente criado e promulgado por um rei para uso de um povo, por autores e em data precisamente conhecidos. À época da criação, era composto de 11 vogais e 17 consoantes. Hoje, usam-se 10 vogais e 14 consoantes básicas. O seu idealizador foi o Rei Sejon ${ }^{g}$, o Grande (1397 1450), quarto rei da Dinastia Lee, que encomendou a um grupo de estudiosos um sistema capaz de representar os sons coreanos. Desenvolvido ao longo de 3 anos e concluído em 1443, o hangul foi promulgado em 1446, sob a denominação "Sons corretos para serem ensinados ao povo". O resultado foi um alfabeto, fonético, atrasado em vários séculos em relação aos silabários kana japoneses. 
O documento original do "Sons corretos para serem ensinados ao povo", o Hun-min-jón ${ }^{g}$-um, é um verdadeiro tratado de fonética e ortografia que explica o motivo da criação, os princípios, detalhes de utilização com exemplos de funcionamento do hangül, e começa dizendo:

Os sons do nosso idioma diferem dos do chinês, e não podem ser facilmente transmitidos por meio dos ideogramas chineses. Muitos entre os não ilustrados, ainda que desejam expressar seus sentimentos por escrito, não o podem. Compadecendo-me desta situação, idealizei 28 novas letras. Desejo apenas que o povo possa aprendê-las facilmente e usá-las convenientemente na sua vida diária.

Quanto aos caracteres, o Hun-Min-Jón $n^{g}-U m$ esclarece que as letras criadas são hieroglíficas - icônicas, diríamos hoje -, com as consoantes imitando a conformação dos órgãos fonadores ao articular aquele som. As vogais, por sua vez, seriam combinações de três conceitos traduzidos iconicamente: o céu $(\bullet)$, a terra (一) e o homem ( l ). A adoção de padrões gráficos totalmente diferentes para as vogais e para as consoantes é um fator de grande prestígio do hangul entre os lingüistas.

O princípio básico da escrita coreana é o que poderíamos chamar de "montagem silábica". As letras são literalmente "montadas", como se fosse um "lego", dentro de quadrados imaginários - uma sílaba - num sistema tripartite de sons, chamados respectivamente de consoante inicial, vogal e consoante final, como por exemplo, numa sílaba como "pam". A menor combinação possível é de dois sons, uma consoante e uma vogal, como em "pa". Assim, para grafar "a" por exemplo, precisaremos de, no mínimo, dois elementos; no caso, uma consoante neutra e a vogal correspondente a "a".

A montagem das letras dentro de um quadrado imaginário segue uma regra direcional básica: da esquerda para a direita e de cima para baixo. É curioso como o princípio de montagem ideográfica foi transposto para uma montagem fonética: enquanto a montagem ideográfica resulta numa idéia, a fonética redunda numa sílaba. Em outras palavras, o alfabeto é fonético, porém, a escrita é silábica. 
Figura 5: exemplo de um texto coreano

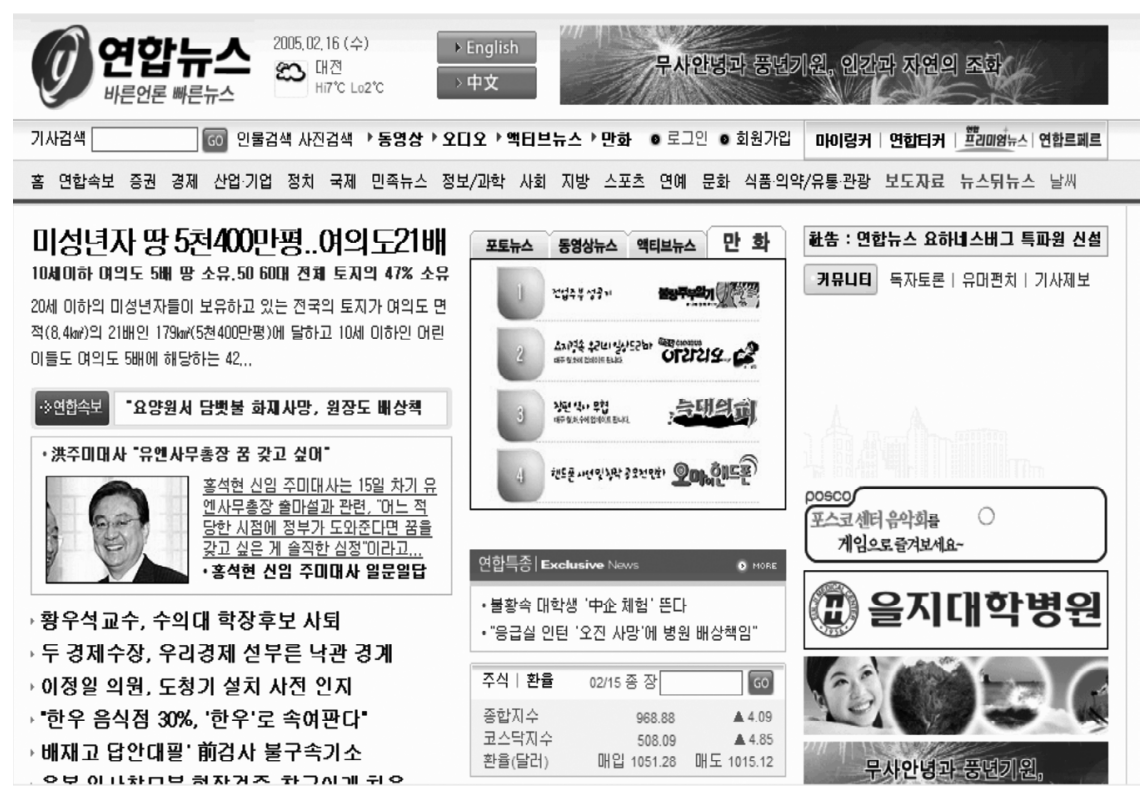

\section{A armadilha do hangul}

Posto assim, o hangul parece ser um sistema original, autêntico e independente, imagem vendida pelo governo coreano no mundo. $\mathrm{O}$ marketing deu tão certo que o prêmio da Unesco em prol da erradicação do analfabetismo no mundo chama-se Prêmio Rei Sejong. Qualquer lingüista coreano vangloria-se de possuir um sistema de escrita totalmente próprio, claro, sistemático, fácil de ser aprendido, quase um esperanto da escrita que deu certo.

Porém, a propalada independência tardaria, e muito, a vingar. A polemização não vem de um lingüista mas de um filósofo, Do-or, através de observações espalhadas em sua obra "Orientalismo: o que fazer?", escrito em 1986. Graduação em filosofia na Coréia, mestrado sobre Lao-Tsé na Universidade Nacional de Taiwan, um segundo mestrado sobre neo-confucionismo na Universidade de Tóquio, Japão, e doutorado sobre a hermenêutica do I Ching em Harvard credenciam Do-or a transitar livremente pelas três línguas e compará-las 
com conhecimento de causa. Embora não seja lingüista, tem como sua maior colaboradora a esposa, uma lingüista sinóloga.

Segundo Do-or, a grande diferença no processo de adaptação do chinês dos japoneses e dos coreanos foi que os primeiros leram os ideogramas pelo significado enquanto que os últimos os leram pelo significante. Exemplificando, o japonês escreve o ideograma 道 (caminho) - lido em chinês como tao - e o lê como mitchi, que é "caminho" em japonês. Ou seja, vê o ideograma chinês e o lê traduzido. Já o coreano lê o mesmo ideograma como dô - adaptação do som tao para os padrões sonoros coreanos -, e não como kil, que seria "caminho" em coreano. Ou seja, não ocorre o processo de tradução do significado, mas sim uma adaptação do significante. Num exemplo mais próximo, seria a mesma diferença de se ler os ideogramas 周易 como I Ching e como "Livro das Mutações": a primeira leitura é sonora e a segunda, conteudística.

Voltando ao exemplo do "caminho", os japoneses também podem ler o ideograma como dô, -como em cha-dô, cerimônia do chá - geralmente em palavras compostas. Assim, os ideogramas acabam por receber pelo menos duas leituras, a leitura pelo significado e pelo significante. Já no coreano, há somente a segunda opção. Para Do-or, ler o ideograma 道 como "caminho" e como "dô" representam duas posturas distintas de assimilar uma escrita. Para ele, os japoneses de fato TRADUZIRAM o chinês, trazendo o ideograma para o território japonês, enquanto que os coreanos optaram por deixá-lo no território do estrangeiro lendo-o pelo significante.

Segundo ele, os japoneses reconheceram logo a diferença e buscaram um meio para resolvê-la, promovendo uma verdadeira mistura do outro e de si e fundando um sistema baseado na adaptação, tradução, assimilação e flexibilidade, que inclusive tinha a vantagem de não romper em definitivo como todo o acervo cultural documentado em ideogramas chineses. A Coréia, além de ter sido um dos últimos países periféricos à China a criar uma escrita própria, e pelo menos 600 anos atrasada em relação aos japoneses, criaram um sistema que, pela falsa idéia da independência, relegou o hangul a uma geladeira de quase 500 anos, uma vez que a classe nobre desprezou-o desde o início, passando ele a ganhar território definitivo somente no início do século passado, como uma reação à dominação japonesa. Tal segregação não ocorreu no Japão, sendo os silabários rapidamente difundidos por toda a população. Com isso, o atraso coreano vai para mais de um milênio! 
Entre os coreanos, as escritas coreana e a chinesa sempre foram duas coisas distintas, obrigando-se a optar entre um e outro. Assim, a postura da classe dominante foi conservadora e elitista em detrimento da difusão do hangul. Segundo Do-or, isso ocorreu porque na Coréia não houve a "tradução" do chinês, como no Japão. Sendo a tradução um movimento pela democratização, popularização e difusão do conhecimento, o resultado foi justamente o oposto da intenção do Rei Sejon ${ }^{\mathrm{g}}$ e do que prega a instituição governamental coreana.

\section{A HORA E A VEZ DO HANGUL}

No entanto, não é de cruxificar a pretensa independência do hangul por esse atraso, pois, como veremos, a independência tarda, porém, chega, num processo lento que se encontra ainda em curso.

Como foi dito, os japoneses e os coreanos importaram a escrita chinesa, mas somente a escrita, pois, sendo falantes de línguas não-tonais, tiveram que "adaptar" sons próprios para cada ideograma. Nesse processo, ocorreu um achatamento dos tons, fazendo igualar, digamos, 4 tons diferentes no chinês. A limitação fonética do silabário japonês é maior que a do coreano, fazendo com que um número ainda maior de ideogramas chineses sejam lidos da mesma forma. Haroldo de Campos, grande admirador e conhecedor da literatura japonesa, via nesse fato rica possibilidade para jogos poéticos sonoros. Uma vez que os próprios ideogramas fazem parte orgânica do texto, a questão da homofonia não se torna tão problemática, pelo menos quando acompanhado do texto escrito. Porém, no caso de um texto em coreano, muitas vezes é necessário abrir um parênteses para inserir o ideograma que se quer dizer, já que as palavras homófanas também são homógrafas.

Mesmo quando o hangul começou a ser difundido entre a população no início do século 21, a escrita coreana também cumpria uma função semelhante à do hiragana até uma boa parte da segunda metade do século, servindo de "liga" numa sentença onde vocábulos grafados em ideogramas chineses eram as peçaschaves lexicais. No entanto, a partir da década de 70, ocorre um gradual abandono dos ideogramas chineses, substituídos aos poucos pelo léxico correspondente na língua nativa coreana. Cabe observar que o léxico nativo coreano é dotado de rica sonoridade, com abundância de palavras 
onomatopaicas. Da passagem de uma língua tonal para uma não-tonal, o léxico de origem chinesa perdeu a riqueza sonora em detrimento da orquestração que lhes é própria, e é justamente essa música da fala nativa coreana que vem sendo recuperada nas últimas décadas. Esse processo de substituição ainda está em curso, com novos vocábulos recuperados entrando em circulação a cada dia, numa lenta jornada de conquista da verdadeira independência.

\section{O CASO DA CORÉIA DO NORTE}

A Coréia do Norte, por exemplo, optou por priorizar o vocabulário nativo desde a sua fundação há pouco mais de cinqüenta anos, como parte do movimento de extrema-direita nacionalista. Muitas palavras utilizadas pelos norte coreanos são estranhos, e, em alguns casos, até motivo de risada por parte dos sul-coreanos, como por exemplo a palavra "sutiã", que é expresso como "embrulhador de seios". E as diferenças já estavam ultrapassando os limites do léxico, chegando a afetar a desinência das flexões. Assim, tem ocorrido alguns movimentos no sentido de se padronizar as duas línguas, através de comissões conjuntas.

\section{LÍNGUA-CULTURA}

Por fim, vale comentar alguns indicativos culturais que podem ser inferidos dos dois processos de adaptação da escrita chinesa. Enquanto o processo japonês foi de assimilar, adaptar e amalgamar os elementos exógenos com os seus para chegar numa unidade composta, o coreano optou pela invenção de um sistema de escrita totalmente novo. Um episódio da história coreana pode ilustrar esse tipo de atitude: a Dinastia Joson, confucionista, foi instituída em 1392 sobre o reino de Koryo, em que a religião oficial era o budismo. A nova ordem baniu a religião milenar de forma tão radical que muitos templos foram queimados e obrigados a se refugiarem para as montanhas, e as imagens de buda que permaneceram tiveram as cabeças cortadas e enterradas. Essa radicalidade também se manifestou no final do século 19 quando os navios estrangeiros de diferentes 
nacionalidades tentaram se aproximar da costa coreana e eram recebidos a flechadas, fazendo a Coréia merecer o apelido de "país ermitão".

O segundo traço a notar é a maior propensão dos coreanos para o som, enquanto o sistema japonês mostra uma predileção pelo visual. Essa pode ser uma observação puramente impressionista, mas o haikai, o teatro nô, e a forma pela qual a escrita chinesa foi adaptada fazem transparecer um mundo silencioso e fortemente visual. O sijô, que seria a forma coreana correspondente ao haikai japonês era poesia para ser entoada e cantada. Vale também lembrar que o léxico nativo coreano é ricamente onomatopaico, com as onomatopéias classificadas em "onomatopéias de som" e "onomatopéias de forma", por estranho que isso possa parecer. E foi o gosto pelo som dos coreanos que se traduziu na criação do hangul, adaptando o conceito de montagem ideogrâmica para uma montagem fonética.

\begin{abstract}
For long time, Koreans and Japanese had the Chinese ideograms as the only means for documentation, instruction and education. In other words, Koreans and Japanese, speakers of ural-altaic languages, were obliged to write in an sino-tibetan language. To overcome this gap, both developed their own writing systems, where the Chinese ideograms were the starting point. These were really a translation process, which reveal different means to deal with the difference.
\end{abstract}

Key words: Korean, Japanese, Chinese, translation 
